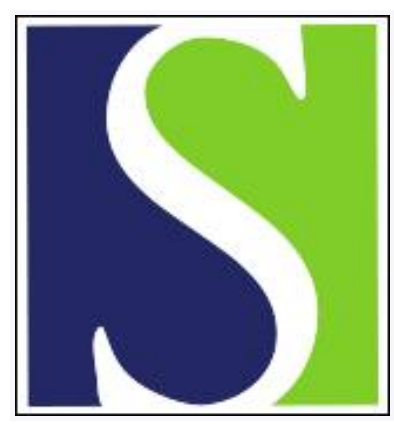

Scand J Work Environ Health 2003;29(2):117-123

https://doi.org/10.5271/sjweh.713

Issue date: Apr 2003

Impact of ergonomic intervention on back pain among nurses

by Smedley J, Trevelyan F, Inskip H, Buckle P, Cooper C, Coggon D

Affiliation: MRC Environmental Epidemiology Unit, Southampton General Hospital, Southampton, SO16 6YD, United Kingdom. jcs@mrc.soton.ac.uk

Refers to the following text of the Journal: 1995;21(6):435-439

The following article refers to this text: 2018;44(2):113-133

Key terms: back pain; ergonomic intervention; health personnel; in-service training; lifting; low-back pain; nurse; occupational health; patient handling

This article in PubMed: www.ncbi.nlm.nih.gov/pubmed/12718497 


\title{
Impact of ergonomic intervention on back pain among nurses
}

\author{
by Julia Smedley, FFOM, ${ }^{1}$ Fiona Trevelyan, PhD, ${ }^{2}$ Hazel Inskip, PhD, ${ }^{1}$ Peter Buckle, PhD, ${ }^{2}$ Cyrus Cooper, \\ FRCP, ${ }^{1}$ David Coggon, FFOM ${ }^{1}$
}

\author{
Smedley J, Trevelyan F, Inskip H, Buckle P, Cooper C, Coggon D. Impact of ergonomic intervention on back pain \\ among nurses. Scand J Work Environ Health 2003;29(2):117-123.
}

Objectives This study assessed the impact of ergonomic intervention on rates of low-back pain among hospital
nurses.
Methods Altogether 1239 female nurses from two hospitals in southern England completed a baseline postal
questionnaire about low-back pain and associated risk factors. Between 18 and 28 months after the baseline
survey, major intervention was implemented at one hospital to minimize unassisted patient handling and high-
risk nursing tasks. At the other, no intervention was initiated, and efforts to improve patient handling were more
limited. Thirty-two months after the baseline survey, a second postal survey was carried out in both hospitals
(1167 respondents) to reassess the prevalence of symptoms and risk factors.
Results After adjustment for nonoccupational risk factors, prevalent low-back pain at baseline was associated
with low job satisfaction and the performance of patient-handling activities without mechanical aids. After the
intervention, the prevalence of occupational risk factors was somewhat lower, but similar improvements oc-
curred at the comparison hospital. At the intervention site the prevalence of symptoms increased slightly (from
$27 \%$ to $30 \%$ ), whereas at the comparison site there was no change, the prevalence remaining constant at $27 \%$.
Calculations based on the association of risk factors with symptoms at baseline and the observed changes in their
prevalence indicated that the change in risk factors was insufficient to produce a substantial reduction in back
pain.

Conclusions These findings cast doubt on the means by which many hospitals are attempting to improve the ergonomics of nursing activities. More effective methods of implementing changes in work systems are needed.

Key terms low-back pain, lifting, patient handling, occupational health, health personnel, in-service training.

Low-back pain is a major cause of morbidity in the general population, and a common reason for absence from work (1). It is a particular problem among nurses, with costs for lost manpower, litigation, and compensation for the British National Health Service (NHS) (2, 3). In Great Britain, health and safety legislation requires employers to identify occupational hazards for musculoskeletal diseases among their workforces and to reduce the associated risks when practical. Motivated by this legislation and by the desire to care for their employees and at the same time reduce costs, many NHS hospitals have attempted to improve the ergonomics of nursing tasks. The actions taken have included the introduction of mechanical aids such as hoists, belts, and sliding sheets for lifting and moving patients and training in techniques in patient handling.

The basis for such intervention lies in ergonomic theory (4) and in the results of epidemiologic studies of risk factors associated with prevalent (5-8) and incident (910) back pain among nurses. As yet, however, there have been few attempts to assess the benefits directly. This step is important because poor physical work systems are not the only risk factor for back pain. Other aspects of the work system, including psychosocial influences, are also relevant, as are individual psychological attributes (10-12). It is conceivable that an intervention program, by raising employees' awareness of back problems, might even lead to an increase in the

1 Environmental Epidemiology Unit, Medical Research Council, Community Clinical Sciences, University of Southampton, Southampton, United Kingdom.

2 Robens Centre for Health Ergonomics, European Institute of Health and Medical Sciences, University of Surrey, Surrey, United Kingdom.

Reprint requests to: Dr Julia Smedley, MRC Environmental Epidemiology Unit, Southampton General Hospital, Southampton, SO16 6YD, United Kingdom. [E-mail: jcs@mrc.soton.ac.uk] 
reporting of symptoms and sickness absence. On the other hand, if it could be established that there are major gains from improvements in the work systems involved in nursing activities, it would be an encouragement to embrace such changes more widely and completely than at present.

We therefore carried out a study at two NHS hospitals in the United Kingdom to assess the impact on rates of back pain after attempts to improve methods of patient handling of the type that many hospitals are adopting. One hospital acted as the intervention site; the other served as a comparison.

\section{Subjects and methods}

The two participating hospitals were located in the south of England and provided acute medical and surgical services to their surrounding communities. At each hospital a baseline postal questionnaire was sent to all nurses on the payroll other than midwives and those based in the community. Among other things, the questionnaire covered age, gender, height, weight, detailed occupation, frequency of specified occupational activities, perceived levels of psychosocial stressors in work, frequent occurrence of low mood or stress, and history of low-back pain lasting more than a day during the past month. The questions concerning psychosocial stressors were taken from the Whitehall II study (13), and they were used to classify persons in relation to five dimensions covering job demand, interest, control, support, and satisfaction. Each dimension was graded to three levels with cut-points as close as possible to tertiles of the relevant point score. The anatomic region covered by the term "low back" (twelfth ribs to gluteal folds) was defined by a shaded area in a diagram. This means of ascertaining low-back pain has good reproducibility (14) and has been used in several previous studies with general populations $(15,16)$, and with nursing populations $(7,8)$. A one-month period was chosen in order to optimize symptom recall. Nonrespondents were sent a reminder after 6 weeks.

Between 18 and 28 months after the baseline survey, an intervention was implemented at one of the two sites. It centered on the revision of the hospital-wide manual-handling policy to minimize unassisted patient handling and exposure to high-risk nursing tasks. Managers from every level of the organization were engaged in an attempt to bring about major cultural change and raise the profile of risk controls. This work included meetings with the Operational Board and awareness sessions for the Health and Safety Advisory Committee and for ward-based managers. All members of the staff were informed about the managerial commitment to the new policy through regular team briefing bulletins. The hos- pital purchased 700 new sliding sheets, which were distributed to all the wards. The intervention also entailed provision of additional lifting and handling equipment, worth GBP 200000 , including hi/lo baths, hoists, transfer belts and sliding sheets, the equipment being distributed at ward level in the general medicine and intensive care, orthopedics and surgery departments. These clinical areas had been identified as priority for change because it appeared that nurses working in these units carried out the largest number of patient-handling tasks. In the same departments, a member of the research team, who was trained as an ergonomist (FT), established a network of ward-based "link nurses" to facilitate ownership of the intervention throughout the organization. The link nurses acted as a contact point in each ward and were instrumental in the dissemination of information to their colleagues. Training of the link nurses was provided in the form of specialty-specific workshops and focus groups aimed at identifying and developing solutions to difficult handling problems. The link nurses did not train their colleagues in practical techniques, but, when requested by a link nurse, practical instruction was delivered by the health and safety team, ergonomist, or the manufacturers of hoisting equipment. The role of link nurses included ensuring that equipment was both easily accessible to nurses and in good functional order. Regular maintenance was carried out by the manufacturers. In addition, all the employees were offered a 2day training course in health and safety that incorporated basic aspects of manual handling. This course was attended by almost all of the nurses working for the hospital.

At the second, "comparison" site, the study team made no intervention. However, following a visit by a representative of the Health and Safety Executive in 1998, management at the hospital took steps to improve the manual-handling training program provided for nursing staff and extend the use of patient-handling equipment in the wards. This development coincided with the introduction of the ergonomic program at the "intervention" hospital. Although the efforts at improvement at the comparison site were not recorded formally, our observations suggest that they were more limited than at the intervention hospital.

Thirty-two months after the baseline survey, a second postal survey was carried out at both hospitals. Nurses were sampled as at baseline, and were sent a questionnaire similar to that used in the original survey. Nonrespondents were sent reminders after 6 weeks, and, if necessary, again after a further 16 weeks.

Statistical analysis was carried out with the STATA software package (14). Data from the baseline survey at the two hospitals were combined and used to explore the cross-sectional association of low-back pain in the past month with constitutional, psychosocial, and ergonomic risk factors. Relationships were summarized by 
prevalence ratios (PR) with 95\% confidence intervals (95\% CI). They were derived by generalized linear modeling with a log link and binomial error structure (15). When examining the risks associated with manual handling, we focused on seven activities that might have been expected to change as a result of the intervention.

We next examined the prevalence of psychosocial and physical risk factors and that of back pain at each of the two hospitals in the follow-up survey as compared with the baseline levels. Finally, we estimated the change in symptom prevalence that might have been predicted after the intervention from changes in the frequency of risk factors and from the strength of their cross-sectional associations with baseline back pain.

\section{Results}

The baseline questionnaire was completed by 1239 nurses (56\% of those mailed). The follow-up questionnaire was answered by 1167 nurses (55\% of those approached), including 558 who had also taken part in the baseline survey. Twenty-nine subjects (19 from the baseline survey and 10 from the follow-up) were exclud- ed because their questionnaire responses indicated employment in midwifery or nonnursing jobs. In both surveys, more than $90 \%$ of the participants were women, and all subsequent analyses were restricted to women. Table 1 summarizes the characteristics of the women who responded to the two surveys. The response rates were slightly higher in the comparison hospital than in the intervention one, but, within each hospital, they were similar at the baseline and follow-up (61\% versus 58\% and $54 \%$ versus $55 \%$ ). In general, the distribution of subjects by age, workhours, grade, and specialty was similar in the two hospitals, both at baseline and at follow-up, except that there were no pediatric nurses working in the comparison hospital. In addition, because of a change in the organization of payroll records, health care assistants were excluded from the follow-up survey in the comparison hospital.

The one-month prevalence of low-back pain at baseline in the two hospitals combined was $27 \%$. The symptom was reported the most frequently by nurses with a body mass index (BMI) of $\geq 30 \mathrm{~kg} / \mathrm{m}^{2}$ (one-month prevalence $38 \%$, PR (compared with BMI $<20 \mathrm{~kg} / \mathrm{m}^{2}$ ) 1.5 (95\% CI 1.0-2.4), but it was not consistently related to age, height, or weight.

Table 1. Characteristics of the women who took part in the surveys. ${ }^{a, b}$

\begin{tabular}{|c|c|c|c|c|c|c|c|c|}
\hline \multirow{3}{*}{ Characteristic } & \multicolumn{4}{|c|}{ Intervention hospital } & \multicolumn{4}{|c|}{ Comparison hospital } \\
\hline & \multicolumn{2}{|c|}{$\begin{array}{l}\text { Baseline } \\
(\mathrm{N}=817)\end{array}$} & \multicolumn{2}{|c|}{$\begin{array}{l}\text { Follow-up } \\
(\mathrm{N}=837)\end{array}$} & \multicolumn{2}{|c|}{$\begin{array}{l}\text { Baseline } \\
(\mathrm{N}=340)\end{array}$} & \multicolumn{2}{|c|}{$\begin{array}{l}\text { Follow-up } \\
(\mathrm{N}=241)\end{array}$} \\
\hline & $\mathrm{N}$ & $\%$ & N & $\%$ & N & $\%$ & N & $\%$ \\
\hline \multicolumn{9}{|l|}{ Age (years) } \\
\hline$<30$ & 162 & 20 & 160 & 19 & 68 & 20 & 48 & 20 \\
\hline $30-39$ & 293 & 36 & 291 & 35 & 96 & 29 & 82 & 35 \\
\hline $40-49$ & 200 & 25 & 213 & 26 & 102 & 30 & 59 & 25 \\
\hline$\geq 50$ & 156 & 19 & 157 & 19 & 70 & 21 & 47 & 20 \\
\hline \multicolumn{9}{|l|}{ Workhours } \\
\hline Part-time & 369 & 45 & 367 & 44 & 172 & 51 & 111 & 46 \\
\hline Full-time & 443 & 55 & 464 & 56 & 166 & 49 & 128 & 54 \\
\hline \multicolumn{9}{|l|}{ Grade } \\
\hline Health care assistant & 141 & 17 & 131 & 16 & 65 & 19 & - & 0 \\
\hline Enrolled nurse & 40 & 5 & 36 & 5 & 22 & 6 & 3 & 1 \\
\hline Staff nurse & 469 & 58 & 496 & 62 & 176 & 52 & 158 & 70 \\
\hline Sister & 78 & 10 & 45 & 6 & 42 & 12 & 39 & 17 \\
\hline Clinical nurse specialist & 44 & 5 & 58 & 7 & 21 & 6 & 15 & 7 \\
\hline Other & 43 & 5 & 32 & 4 & 14 & 4 & 11 & 5 \\
\hline \multicolumn{9}{|l|}{ Specialty } \\
\hline Medicine & 201 & 25 & 234 & 30 & 52 & 16 & 32 & 14 \\
\hline Surgery & 160 & 20 & 117 & 15 & 66 & 20 & 34 & 15 \\
\hline Theater & 106 & 13 & 99 & 13 & 39 & 12 & 36 & 16 \\
\hline Orthopedics & 81 & 10 & 71 & 9 & 47 & 14 & 27 & 12 \\
\hline Outpatients & 64 & 8 & 53 & 7 & 41 & 12 & 17 & 8 \\
\hline Pediatrics & 103 & 13 & 105 & 14 & - & 0 & - & 0 \\
\hline Intensive care & 45 & 6 & 35 & 5 & 13 & 4 & 20 & 9 \\
\hline Obstetrics \& gynecology & 3 & 0 & 4 & 1 & 51 & 15 & 26 & 12 \\
\hline Other & 50 & 6 & 50 & 7 & 25 & 7 & 33 & 15 \\
\hline
\end{tabular}

a Questionnaires had been sent to 1599 nurses in the intervention hospital and 601 nurses in the comparison hospital at baseline and the corresponding numbers for the follow-up were 1664 and 441, respectively.

b Totals do not always sum to the number of respondents due to missing answers on some questionnaires. 
Low-back pain was more common among the women who reported that they were frequently low in mood or spirits, tense or stressed (PR adjusted for BMI 1.7, 95\% CI 1.4-2.0), and it was also associated with psychosocial stressors specifically related to work, the risk being higher when the nurse perceived her job as entailing higher demands and lower interest, control, support, and satisfaction (table 2). The strongest relation was with low job satisfaction, and once this factor was

Table 2. Risk of low-back pain in the past month at baseline according to the perceived psychosocial stresses in the workplace. ( $\mathrm{PR}=$ prevalence ratio, $95 \% \mathrm{Cl}=$ confidence interval)

\begin{tabular}{lcccc}
\hline Risk factor & $\begin{array}{c}\text { Number } \\
\text { exposed }\end{array}$ & $\begin{array}{c}\text { Prevalence of } \\
\text { low-back pain } \\
(\%)\end{array}$ & $\mathrm{PR}^{\mathrm{a}}$ & $95 \% \mathrm{Cl}$ \\
\hline Demand & & & & \\
$\quad$ Low & 318 & 21 & 1 & \\
$\quad$ Intermediate & 457 & 28 & 1.3 & $1.0-1.7$ \\
$\quad$ High & 359 & 33 & 1.4 & $1.1-1.8$ \\
Interest & & & & \\
$\quad$ High & 372 & 22 & 1 &. \\
$\quad$ Intermediate & 398 & 28 & 1.2 & $1.0-1.6$ \\
$\quad$ Low & 363 & 32 & 1.4 & $1.1-1.8$ \\
Control & & & & \\
$\quad$ High & 360 & 22 & 1 &. \\
$\quad$ Intermediate & 402 & 24 & 1.1 & $0.8-1.4$ \\
$\quad$ Low & 368 & 35 & 1.5 & $1.2-1.9$ \\
Support & & & & \\
$\quad$ High & 341 & 27 & 1 &. \\
$\quad$ Intermediate & 422 & 22 & 0.8 & $0.6-1.0$ \\
$\quad$ Low & 272 & 37 & 1.2 & $1.0-1.6$ \\
Satisfaction & & & & \\
$\quad$ High & 282 & 18 & 1 &. \\
$\quad$ Intermediate & 456 & 24 & 1.3 & $0.9-1.7$ \\
$\quad$ Low & 357 & 37 & 1.8 & $1.3-2.4$ \\
\hline
\end{tabular}

a Adjusted for body mass index and frequent occurrence of low mood or spirits or occurrence of tension or stress.

Table 3. Risk of low-back pain in the past month at baseline according to the range of activities performed in an average shift without aids. ( $\mathrm{PR}=$ prevalence ratio, $95 \% \mathrm{Cl}=$ confidence interval)

\begin{tabular}{ccccc}
\hline $\begin{array}{l}\text { Number of different } \\
\text { activities performed } \\
\text { unaided }^{\text {a }}\end{array}$ & $\begin{array}{c}\text { Number } \\
\text { exposed }\end{array}$ & $\begin{array}{c}\text { Prevalence of } \\
\text { low-back pain } \\
(\%)\end{array}$ & $\mathrm{PR}^{\mathrm{a}}$ & $95 \% \mathrm{Cl}$ \\
\hline 0 & 111 & 16 & 1 & \\
1 & 65 & 22 & 1.1 & $0.6-2.2$ \\
2 & 95 & 24 & 1.6 & $0.9-2.8$ \\
3 & 128 & 20 & 1.1 & $0.6-2.0$ \\
4 & 170 & 30 & 2.0 & $1.2-3.3$ \\
5 & 151 & 33 & 1.9 & $1.1-3.1$ \\
6 & 119 & 34 & 2.0 & $1.2-3.3$ \\
7 & 34 & 41 & 2.4 & $1.4-4.3$
\end{tabular}

a The activities considered were transferring a patient from a sitting position to another sitting position, repositioning a patient who has slumped in a chair, assisting a patient to move up or down the bed, repositioning (turning or rolling) a patient in bed, transferring a patient in or out of a bath, assisting or lifting a patient lying on the floor back to a bed or a chair, and transferring a patient between a bed and trolley using poles and a canvas.

${ }^{b}$ Adjusted for level of satisfaction with work, body mass index, and frequent occurrence of low mood or spirits or occurrence of tension or stress. entered into a regression model, none of the other occupational psychosocial stressors was significant.

Table 3 summarizes the relation of low-back pain at baseline to the performance of patient-handling activities without the use of mechanical aids. After adjustment for potential confounding factors, the risk tended to increase with the number of such activities reported, although the trends were not completely uniform. Of the specific activities examined, risk was highest for assisting a patient on the floor to rise onto a bed or chair without the use of handling aids or help from colleagues (PR $1.6,95 \%$ CI 1.2-2.2, for those who performed this task one or more times per shift compared with those who did not).

Table 4 compares the distribution of psychosocial stressors at the two participating sites before and after the intervention. At both hospitals there was some improvement in the levels of stressors over the period of study. In particular, the proportion of nurses in the intervention hospital with low job satisfaction fell from $35 \%$ to $26 \%$.

Figure 1 shows the frequency with which the patienthandling activities analyzed in table 3 were reported at each hospital at baseline and at follow-up. The profiles of the two hospitals were similar at baseline, and after the intervention there was some decrease in the number of patient-handling activities performed without mechanical aids. If anything, however, the reduction was greater in the comparison hospital than in the

Table 4. Percentage distribution of the psychosocial stressors at baseline and at follow-up.

\begin{tabular}{|c|c|c|c|c|}
\hline \multirow[t]{2}{*}{ Risk factor } & \multicolumn{2}{|c|}{ Intervention hospital } & \multicolumn{2}{|c|}{ Comparison hospital } \\
\hline & $\begin{array}{l}\text { Baseline a } \\
(\mathrm{N}=729)\end{array}$ & $\begin{array}{l}\text { Follow-up a } \\
(\mathrm{N}=743)\end{array}$ & $\begin{array}{l}\text { Baseline a } \\
(\mathrm{N}=311)\end{array}$ & $\begin{array}{l}\text { Follow-up a } \\
(\mathrm{N}=213)\end{array}$ \\
\hline \multicolumn{5}{|l|}{ Demand } \\
\hline $\begin{array}{l}\text { Low } \\
\text { Intermediate } \\
\text { High }\end{array}$ & $\begin{array}{l}28 \\
41 \\
32\end{array}$ & $\begin{array}{l}29 \\
44 \\
27\end{array}$ & $\begin{array}{l}29 \\
40 \\
31\end{array}$ & $\begin{array}{l}23 \\
47 \\
30\end{array}$ \\
\hline \multicolumn{5}{|l|}{ Interest } \\
\hline $\begin{array}{l}\text { High } \\
\text { Intermediate } \\
\text { Low }\end{array}$ & $\begin{array}{l}34 \\
34 \\
33\end{array}$ & $\begin{array}{l}36 \\
35 \\
29\end{array}$ & $\begin{array}{l}30 \\
39 \\
31\end{array}$ & $\begin{array}{l}40 \\
38 \\
22\end{array}$ \\
\hline \multicolumn{5}{|l|}{ Control } \\
\hline $\begin{array}{l}\text { High } \\
\text { Intermediate } \\
\text { Low }\end{array}$ & $\begin{array}{l}31 \\
35 \\
34\end{array}$ & $\begin{array}{l}31 \\
39 \\
30\end{array}$ & $\begin{array}{l}33 \\
37 \\
30\end{array}$ & $\begin{array}{l}42 \\
32 \\
26\end{array}$ \\
\hline \multicolumn{5}{|l|}{ Support } \\
\hline $\begin{array}{l}\text { High } \\
\text { Intermediate } \\
\text { Low }\end{array}$ & $\begin{array}{l}33 \\
42 \\
24\end{array}$ & $\begin{array}{l}39 \\
39 \\
22\end{array}$ & $\begin{array}{l}32 \\
37 \\
31\end{array}$ & $\begin{array}{l}32 \\
41 \\
27\end{array}$ \\
\hline \multicolumn{5}{|l|}{ Satisfaction } \\
\hline $\begin{array}{l}\text { High } \\
\text { Intermediate } \\
\text { Low }\end{array}$ & $\begin{array}{l}26 \\
40 \\
35\end{array}$ & $\begin{array}{l}30 \\
43 \\
26\end{array}$ & $\begin{array}{l}26 \\
46 \\
28\end{array}$ & $\begin{array}{l}32 \\
41 \\
27\end{array}$ \\
\hline
\end{tabular}

a Because some questionnaires were not answered completely, the denominators for the proportions varied by risk factor. The number reported is the lowest denominator for any of the risk factors. 


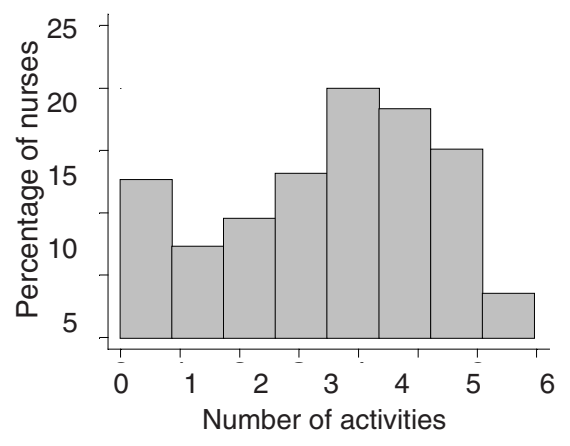

Intervention hospital at baseline

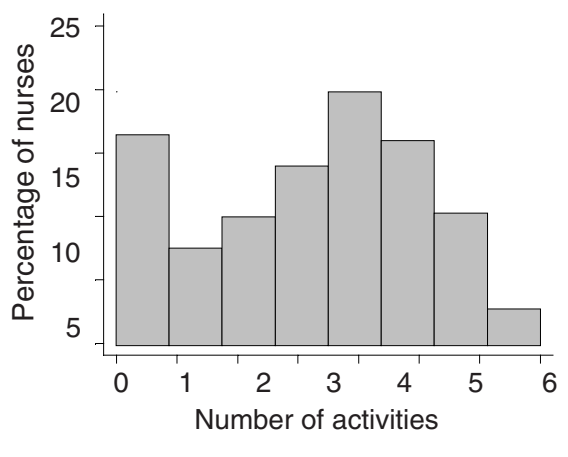

Intervention hospital at follow-up

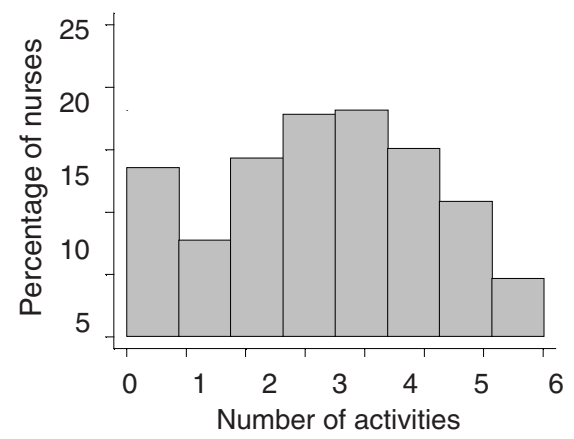

Comparison hospital at baseline

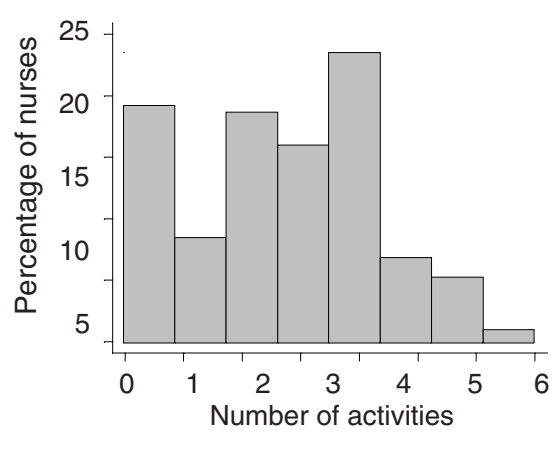

Comparison hospital at follow-up

Figure 1. Distribution of different patient-handling tasks performed during an average workshift without mechanical aids at baseline and at follow-up.

Table 5. One-month prevalence of low-back pain at baseline and at follow-up.

\begin{tabular}{|c|c|c|c|c|c|c|c|}
\hline \multirow[t]{2}{*}{ Hospital } & \multicolumn{2}{|c|}{ Baseline } & \multicolumn{2}{|c|}{ Follow-up } & \multicolumn{2}{|c|}{ Change in \% prevalence } & \multirow[t]{2}{*}{ Predicted change in prevalence a } \\
\hline & $\begin{array}{l}\text { Cases } \\
\text { (N) }\end{array}$ & $\begin{array}{l}\text { Prevalence } \\
(\%)\end{array}$ & $\begin{array}{c}\text { Cases } \\
\text { (N) }\end{array}$ & $\begin{array}{c}\text { Prevalence } \\
(\%)\end{array}$ & $\%$ & $95 \% \mathrm{Cl}$ & \\
\hline Intervention & 222 & 27 & 248 & 30 & $+3 \%$ & $-2 \%-+7 \%$ & $-1 \%$ \\
\hline Comparison & 90 & 27 & 64 & 27 & $0 \%$ & $-7 \%-+8 \%$ & $0 \%$ \\
\hline
\end{tabular}

a The predicted change in prevalence was obtained from a logistic regression model including number of activities performed unaided, level of satisfaction with work, body mass index, and frequent occurrence of low mood or spirits or occurrence of tension or stress.

intervention one (mean number of activities before and after intervention 3.5 and 3.2 , respectively, at the intervention site and 3.3 and 2.6 , respectively, at the comparison site). For each individual activity, the proportion of nurses who reported carrying out the maneuver at least five times in an average workshift also declined, but again the changes were not confined to the intervention hospital.

Table 5 compares the prevalence of symptoms reported at baseline and at follow-up. In the comparison hospital, there was no change in the prevalence of lowback pain between the two surveys, while, in the intervention hospital, the prevalence increased by $3 \%$, a change that was not statistically significant. Table 5 also shows the change in symptoms that would have been predicted from the changes in psychosocial stressors and in the frequency of patient-handling activities that occurred after the intervention. Although there was some improvement in the risk factors, it was too small for any material reduction in back pain to be expected.

When the analysis presented in table 5 was repeated for the wards in the intervention hospital where the intervention had been most intense (general medicine, intensive care, orthopedics and surgery), the results were similar, the predicted change for low-back pain remaining at $-1 \%$ and an observed change of $+2 \%$. When the analysis was restricted to nurses who took part in both the baseline and follow-up surveys, the results of the intervention hospital were again little different from those in table 5 (1-month prevalence of low-back pain $28 \%$ preintervention and $30 \%$ postintervention), although 
a slightly greater increase in the 1-month prevalence was found for the comparison hospital (23\% at baseline and $27 \%$ at follow-up). A repeat analysis excluding the health care assistants who participated in the baseline survey at the comparison hospital also produced very similar findings. (Further information on the additional analyses is available from the authors upon request.)

\section{Discussion}

In this study of nurses, low-back pain was associated both with psychosocial stressors in the workplace and with physical risk factors. Following our intervention at one hospital, there was some reduction in the frequency with which patient-handling activities were carried out without the use of mechanical aids. However, the changes were modest in scale, and little different from those at the comparison hospital, where attempts to improve work methods had been more limited. There was no reduction in the prevalence of symptoms at either hospital.

Self-reported low-back pain was chosen as the main measure of morbidity in our population to ensure the inclusion of symptoms that were of gradual onset and not necessarily associated with a specific incident or accident, sickness absence, or presentation for health care. Exposure to lifting activities was also measured by self-report. Although the exposure was not validated directly, direct observation was carried out among samples of nurses at both hospitals before and after the intervention (data not presented). The pattern of observed activities was broadly compatible with the self-reports from nurses working in similar jobs on similar wards.

Intervention studies of this sort are fraught with practical difficulties. For example, we had planned that the intervention would take place earlier than was eventually achieved and that the main outcomes would be the incidence of back symptoms, sciatica, and associated disability and sickness absence after the intervention as compared with before it. These incidence data were to be collected longitudinally by questionnaires repeated at three monthly intervals as in a previous study (9). However, the loss to follow-up by 2 years from the baseline was such that a reliable assessment of symptoms following the intervention was not going to be possible with this method. Instead, therefore, the impact of the intervention was evaluated by a repeat cross-sectional survey of all nurses at the two hospitals, whether or not they had taken part in or dropped out of the longitudinal component of the study. This procedure gave us larger numbers of subjects for the analysis, but it meant that it was not possible to compare the rates of sciatica, disability, or sickness absence before and after the interven- tion. (The only data about symptom radiation, associated disability, and sickness absence collected in the baseline survey were related to the nurse's entire worklife.)

From a scientific point of view, it would have been better if no workplace changes had occurred in the comparison hospital during the study period, but this situation would not have been ethical. Our approach, therefore, was to try to maximize the improvements in the intervention hospital, while not interfering with any developments that might occur in the comparison hospital. As things turned out, a visit and recommendations from the Health and Safety Executive meant that changes at the comparison hospital were greater than might originally have been expected, although the investment of resources and the effort spent on engaging the cooperation of managers in cultural change throughout the organization was less than in the intervention hospital.

A further unavoidable change (the introduction of a new payroll database) led to the omission of health care assistants from the final survey in the comparison hospital. It is likely that nursing aides have a different pattern of exposure than their qualified nursing colleagues. However, exclusion of care assistants from the baseline data for the comparison hospital had no important effect on the findings.

Another limitation of the study was the incomplete response to the two cross-sectional surveys. It would not be surprising if the nurses who chose to answer our questionnaires differed from the nonrespondents in relation to some of the variables being assessed. They may, for example, have had a higher prevalence of symptoms. This potential for bias is of less concern, however, in the comparison of symptoms before and after the intervention, since at each hospital the response rates to the two surveys were similar.

Despite these weaknesses, the study provides useful information. The cross-sectional association of low-back pain with psychosocial stressors and patient-handling activities is broadly in line with findings from earlier studies of nurses $(5,7,8,10,16-18)$. To some extent, the relation of back pain to reported psychosocial and ergonomic variables may reflect altered perceptions of work as a consequence of the symptoms. However, similar associations with low-back complaints have also been found in longitudinal studies in which risk factors were assessed before symptoms had developed $(9,10)$. In theory, therefore, a reduction in physical risk factors might be expected to lead to fewer symptoms, but we found no evidence of any such benefit from our intervention. Calculations based on risk estimates from the baseline survey suggested that this was the case because the ergonomic improvements were too small. It is also possible that the reporting of low-back pain increased because the intervention heightened awareness among the nurses. 
Our findings illustrate the difficulty in achieving desired changes in work methods through participatory ergonomic intervention, especially in complex organizations such as large hospitals. We cannot exclude the possibility that improvement in the prevalence of symptoms would be apparent with longer follow-up, and, because of the methodological difficulties that we experienced, we cannot rule out a reduction in sickness absence due to improvement in the occurrence of more severe back disorders sufficient to prevent nurses from working or due to the presence of risk controls enabling affected nurses to remain at work or to return to work earlier. However, it seems unlikely that major benefits would accrue without more effective implementation of new work practices.

Some hospitals in the United Kingdom have attempted to bring about more radical changes in patient handling than we were able to achieve. The steps taken have not only included the introduction of equipment and training, but also measures aimed at transforming the whole culture of the organization so that the unassisted lifting and moving of patients and time spent in poor postures are kept to an absolute minimum. In most hospitals in the United Kingdom, however, the response to concerns about back problems among nurses has been more along the lines of our intervention. In addition to the introduction of new equipment valued at GBP 200000 (EUR 327 000), the intervention involved more than seven person-years of staff time, principally for attending training courses. Our findings suggest that even a sizeable investment of this sort may not have the desired effects on work methods or on the rates of back symptoms, at least in the short term.

Further research should focus on ways of achieving more substantial changes in methods of patient handling at reasonable cost. Meanwhile, our results call into question the approaches to the problem that are currently being adopted by many hospitals.

\section{Acknowledgments}

This study was supported by a grant from the NHS South and West Region. We thank the management and staff of the two participating hospitals, especially Peter Fisk, and Arjo Ltd and Medipost Ltd, which helped provide equipment and training. Ian Bowes was responsible for the data management and computing.

\section{References}

1. Clinical Standards Advisory Group . Epidemiology review: the epidemiology and cost of low back pain. London: Her Majesty's Stationery Office; 1994.
2. Buckle P. Epidemiological aspects of back pain within the nursing profession. Int J Nurs Stud 1987;24:319-24.

3. Cowan AF. NHS Pension scheme: ill health retirements. Fleetwood (Lancashire, UK): NHS Pensions Agency; 1999. Report reference TN 13 (99).

4. Baty D, Stubbs DA. Postural stress in geriatric nursing. Int J Nurs Stud 1987;24:339-44

5. Estryn-Behar M, Kaminski M, Peigne E, Maillard MF, Pelletier A, Berthier C, et al. Strenuous working conditions and musculoskeletal disorders among female hospital workers. Int Arch Occup Environ Health 1990;62:47-57.

6. Videman T, Nurminen T, Tola S, Kuorinka I, Vanharanta H, Troup JDG. Low back pain in nurses and some loading factors of work. Spine 1984;9:400-4.

7. Smedley J, Egger P, Cooper C, Coggon D. Manual handling activities and risk of low back pain in nurses. Occup Environ Med 1995;52:160-3.

8. Josephson M, Lagerström M, Hagberg M, Wigaeus-Hjelm E. Musculoskeletal symptoms and job strain among nursing personnel: a study over a three year period. Occup Environ Med 1997;54:681-5.

9. Smedley J, Egger P, Cooper C, Coggon D. Prospective cohort study of predictors of incident low back pain in nurses. BMJ 1997;314:1225-8.

10. Klaber Moffett JA, Hughes GI, Griffiths P. A longitudinal study of low back pain in student nurses. Int J Nurs Stud 1993;30:197-212.

11. Dehlin O, Berg S. Back symptoms and psychological perception of work: a study among nursing aides in a geriatric hospital. Scand J Rehabil Med 1977;9:61-5.

12. Heliövaara $M$, Mäkelä $M$, Knekt $P$, Impivaara $\mathrm{O}$, Aromaa $A$. Determinants of sciatica and low back pain. Spine 1991;16: 608-14.

13. North F, Syme L, Feeney A, Head J, Shipley MJ, Marmot MG. Explaining socio-economic differences in sickness absence: The Whitehall II study. BMJ 1993;306:361-6.

14. Walsh K. Reproducibility of histories of low back pain by self-administered questionnaire. Spine 1991;16:1075-7.

15. Papageorgiou AC, Croft PR, Ferry S, Jayson MIV, Silman AJ. Estimating the prevalence of low back pain in the general population: evidence from the South Manchester back pain survey. Spine 1995;20:1889-94.

16. Palmer KT, Walsh K, Bendall H, Cooper C, Coggon D. Back pain in Britain: comparison of two prevalence surveys at an interval of 10 years. BMJ 2000;320:1577-8.

17. Stata Corporation. Stata statistical software release 6.0. College Station (TX): Stata Corporation; 1999.

18. Zocchetti C, Consonni D, Bertazzi PA. Estimation of prevalence rate ratios from cross-sectional data. Int $\mathrm{J}$ Epidemiol 1995;24:1064-5.

19. Niedhammer I, Lert F, Marne MJ. Back pain and associated factors in French nurses. Int Arch Occup Environ Health 1994;66:349-57.

20. Ahlberg-Hultén GK, Theorell T, Sigala F. Social support job strain and musculoskeletal pain among female health care personnel. Scand J Work Environ Health 1995;21:435-9.

21. Bru E, Mykeltun RJ, Svebak S. Work-related stress and musculoskeletal pain among female hospital staff. Work Stress 1996;10:309-21.

Received for publication: 16 April 2002 